\title{
Leucocyte ascorbic acid and the leucocyte count
}

\author{
BY S. VALLANCE* \\ British Antarctic Survey, Madingley Road, Cambridge $\mathrm{CB}_{3}$ oET
}

(Received I8 April 1978 - Accepted I4 September 1978)

\begin{abstract}
I. During the course of a nutritional survey on an Antarctic base, leucocyte ascorbic acid estimations (Denson \& Bowers, I96I) were found to be significantly affected $(P<0.000 \mathrm{I})$ by the leucocyte count measured during analysis.

2. The effect was significantly less $(P<0.05)$ when leucocyte levels were at or near saturation than when subsaturated.

3. This suggests that leucocytes share available ascorbic acid, especially in subsaturated subjects, and that assessment of nutritional status from the leucocyte ascorbic acid level should take account of the leucocyte count and the plasma ascorbic acid titre.
\end{abstract}

The commonly used method for estimation of leucocyte ascorbic acid content described by Denson \& Bowers (I96I) has been criticized for ignoring the ascorbic acid content of platelets in the buffy layer (Gibson et al. 1966). Fluctuations in the platelet count were shown to considerably affect the measured leucocyte ascorbic acid level using the previouslymentioned technique. Using the same method, inverse relationships between leucocyte ascorbic acid content and the leucocyte count of whole blood have been reported in both healthy subjects (Loh \& Wilson, I97I ; Marchand \& Pelletier, 1977) and hospital patients (MacLennon \& Hamilton, 1976; Vallance et al. 1978; Irvin et al. 1978). It has been suggested that this was the result of migration of ascorbate-rich polymorphs to areas of inflammation and infarction (MacLennon \& Hamilton, 1976; Vallance et al. 1978).

During the course of a survey into the ascorbic acid nutrition of healthy young men on a British Antarctic base (Vallance, I975) it was noted that the leucocyte ascorbic acid levels analysed by the Denson \& Bowers (196I) method were markedly affected by the leucocyte counts measured during analysis. This finding is reported and discussed here.

\section{EXPERIMENTAL}

\section{Subjects and location}

During a year (February 1972-February 1973) on a British Antarctic Survey base (Adelaide Island, $67^{\circ} 46^{\prime} \mathrm{S}, 68^{\circ} 54^{\prime} \mathrm{W}$ ) plasma and leucocyte ascorbic acid levels were measured on eight occasions from the eight men wintering on the base, though for technical reasons the leucocyte levels measured on the first occasion were not considered accurate. Also on several occasions blood ascorbic acid analyses were performed on visitors to the base and subjects resident on the base during the austral summer. In all sixty-eight technically satisfactory leucocyte ascorbic acid estimations were completed.

All subjects were healthy young British males aged 23-37 (mean 27) years. None of the subjects contracted infectious diseases or suffered other than minor physical trauma during the course of the survey.

* Present address: East Birmingham Hospital, Bordesley Green East, Birmingham B9 5 ST.

$0007-1145 / 79 / 3138-1409$ \$or.00 (C) 1979 The Nutrition Society 


\section{Methods}

Ascorbic acid was estimated by the $2: 4$ dinitrophenylhydrazine method of Denson \& Bowers (I96I). The leucocyte counts were performed on a Thoma haemocytometer counting grid of $0.1 \mathrm{~mm}$ depth and single grid area $\mathrm{I} / 400 \mathrm{~mm}^{2}$, under a monoccular field microscope.

The statistical significance of the relationships between leucocyte ascorbic acid levels and leucocyte counts was examined by linear regression analysis. Differences between slopes of regression lines were examined using the theory of correlation.

\section{RESULTS}

A highly significant $(P<0.000 \mathrm{I}, t 7.57)$ inverse relationship was found between leucocyte ascorbic acid content and the leucocyte count (Fig. I). This was much less significant at higher plasma levels. When plasma levels were more than $45 \mu \mathrm{mol} / 1(0.8 \mathrm{mg} / \mathrm{dl}, n=\mathrm{I} 3)$, when leucocyte ascorbic acid levels could be considered at or near saturation, the relationship was only just statistically significant $(0.02<P<0.05)$, and the difference between these blood levels and those of the subsaturated bloods $(n=55)$ was also statistically different $(P<0.05, z 2 \cdot 19)$.

\section{DISCUSSION}

Leucocyte ascorbic acid content is considered to reflect tissue ascorbic acid status (Lowry et al. 1946; Burch, 196r) and therefore nutritional status. Plasma ascorbic acid titre is much less reliable (Burch, I96I), but when followed with serial estimations over a period of time does reflect ascorbic acid intake (Vallance, I975).

In healthy adults leucocytes become fully saturated on ascorbic acid intakes of between 0.66 and $1.7 \mathrm{mg} / \mathrm{kg}$ per d (Belser et al. 1939; Hellman \& Burns, 1958). Ascorbic acid intakes greater than these do not increase the leucocyte content though plasma levels continue to increase (Lowry, 1952; Morse et al. 1956; Goldsmith, 1961; Masek, 1966). On a totally scorbutic diet leucocyte ascorbic acid content decreases to zero approximately 3 months after that of plasma (Crandon et al. 1940).

Despite leucocytes having been observed to absorb ascorbic acid against a concentration gradient (Denson \& Bowers, I96I; Brook \& Grimshaw, I968) the results here confirm the previously reported inverse relationship between leucocyte ascorbic acid content and the leucocyte count. Previous authors (MacLennon \& Hamilton, 1976) have discounted that this might be due to a dilution effect of leucocytes on the available ascorbic acid, but these results indicate that a dilution effect is, at least in part, responsible. In this survey the number of bloods which showed subjects to be at or near saturation was both absolutely and relatively small ( 13 of 68 samples), but the leucocyte ascorbic acid levels were significantly less affected by the leucocyte count than the subsaturated samples. This suggests that, especially in subsaturated subjects, available ascorbic acid is shared by leucocytes, the higher the leucocyte count the lower the leucocyte content, the lower the leucocyte count the higher the leucocyte content. It also suggests that only when ascorbic acid intake is such as to saturate all cells, and this may be judged from the plasma ascorbic acid titre, is the individual capacity of each cell satisfied.

Leucocytosis following myocardial infarction (Vallance et al. 1978), infection (Marchand \& Pelletier, 1977) and surgical trauma (Irvin et al. 1978) has been shown to cause unexpectedly low leucocyte ascorbic acid levels, and there may be a danger, in subsaturated subjects with a leucocytosis due to trauma or infection, that reference to a leucocyte ascorbic acid estimation only may result in a falsely low assessment of nutritional status.

Denson \& Bowers, (196I) method of measuring leucocyte ascorbic acid content is the most widely used and most practical method for most laboratories, though it is obviously not 


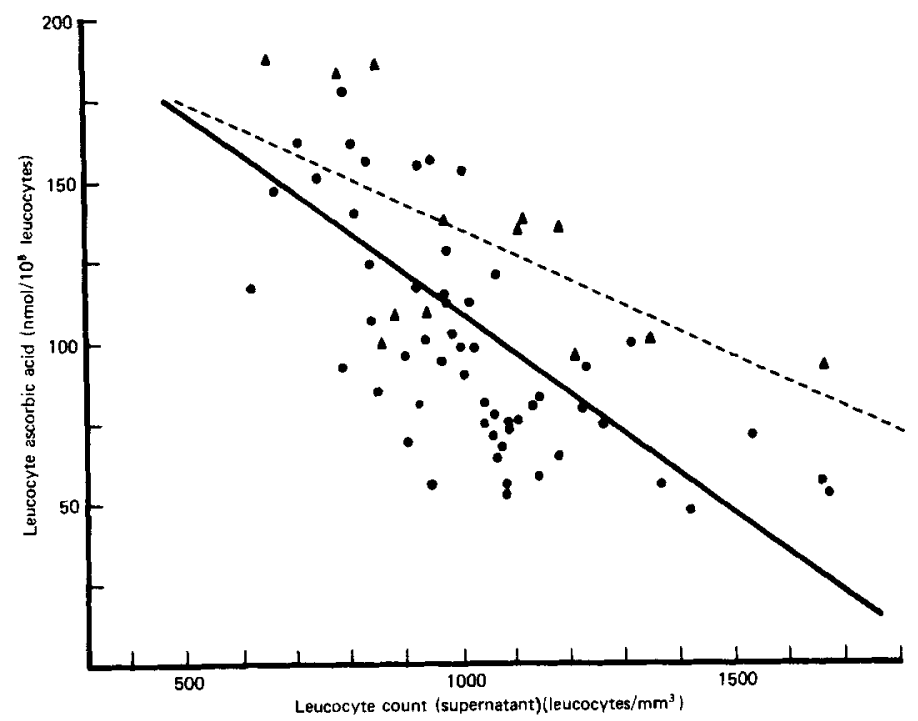

Fig. I. Leucocyte ascorbic acid content in relation to supernatant leucocyte count $(P<0.0001, t 7 \cdot 57)$. - Non-saturated; $\boldsymbol{\Delta}$, saturated; - - , regression for all values; - - , regression for saturated values. (Supernatants resulted from approximately $3 \mathrm{ml}$ of whole blood (EDTA tube filled to $3 \mathrm{ml}$ mark) mixed with $12.5 \mathrm{ml}$ dextravan/saline solution (measured) and allowed to settle for $45 \mathrm{~min}$ ).

perfect. Until a better, equally practical method of leucocyte ascorbic acid estimation is found, leucocyte ascorbic acid content should probably be considered in relation to the leucocyte count and plasma ascorbic acid titre, before conclusions are made about the nutritional ascorbic acid status of hospital patients or subjects of nutritional surveys.

The author thanks Dr Otto Edholm for facilities made available at his now disbanded Division of Human Physiology of the Medical Research Council and Dr Paul Nicholas of Beecham Research Laboratories, Dorking, Surrey, for advice on analytical method, and is indebted to the British Antarctic Survey, who supported the work.

\section{REFERENCES}

Belser, W. B., Hauck, H. M. \& Storvick, C. A. (1939). J. Nutr. 17, 513.

Brook, M. \& Grimshaw, J. J. (I968). Am. J. clin. Nutr. 21, I 254.

Burch, H. B. (196I). Ann. N.Y. Acad. Sci. 92, 268.

Crandon, J. H., Lund, C. C. \& Dill, D. B. (I940). New Engl. J. Med. 223, 353.

Denson, K. W. \& Bowers, E. F. (1961). Clin. Sci. 21, 157.

Gibson, S. L., Moore, F. M. \& Goldberg, A. (I966). Br. Med. J. i, I I 52.

Goldsmith, G. A. (196I). Ann. N.Y. Acad. Sci. 92, 230.

Hellman, L. \& Burns, J. J. (I958). J. biol. Chem. 230, 923.

Irvin, T. T., Chattopadhyay, D. K. \& Smythe, A. (1978). Surgery Gynec, Obstet. 147, 49.

Loh, H. S. \& Wilson, C. W. M. (I97I). Int. J. Vitam. Nutr. Res. 41, 253.

Lowry, O. H. (1952). Physiol. Rev. 32, 432.

Lowry, O. H., Bessey, O. A., Brock, M. J. \& Lopez, J. A. (1946). J. biol. Chem. I66, I I1.

MacLennon, W. J. \& Hamilton, J. C. (1976). Age Ageing 5, 43.

Marchand, C. M. \& Pelletier, O. (1977). Int. J. Vitam. Nutr. Res. 47, 236.

Masek, J. (1966). Rev. Czech. Med. 12, 54.

Morse, E. H., Potgeiter, M. \& Walker, G. R. (1956). J. Nutr. 58, 291.

Vallance, B. D., Hume, R. \& Weyers, E. (I978), Br. Heart J. 40, 64.

Vallance, S. (1975). Br. Antarctic Survey Bull. 41/42, 139. 